\title{
La heterogeneidad de la mirada. Un acercamiento a la imagen fotográfica compleja como dispositivo visual anticolonial
}

The heterogeneity of the gaze. A close up to the photographic complex image as an anticolonial visual dispositive

ISABEL GALINDO AGUILAR*

Escuela Nacional de Antropología e Historia (ENAH) México

* sokosavi@icloud.com

(i) https://orcid.org/0000-0001-5506-8844

di) https://doi.org/10.52948/ds.v3i2.422

Artículo de investigación Recepción: 19 de enero de 2021 Aprobación: 29 de junio de 2021

Cómo citar este artículo:

Galindo Aguilar, I. (2021). La heterogeneidad de la mirada. Un acercamiento a la imagen fotográfica compleja como dispositivo visual anticolonial. Designio, 3(2), 


\section{Resumen:}

El objetivo de este artículo es explicar la heterogeneidad de la mirada y los alcances simbólicos y materiales de la representación, para lo cual se analizan "textos" fotográficos que fueron captados, intervenidos y documentados desde una "mirada anticolonial". Dicha reflexión se realiza a partir de un ejercicio de contraste multilocal-multisituado entre la mirada de tres fotógrafos: Graciela Iturbide de México, Sebastião Salgado de Brasil y Martín Chambi de Perú, quienes tienen diferentes condiciones de raza-clase-género. Además, se explica cómo la mirada colonial del cientificismo racial fue subvertida en el proyecto de intervención fotográfica dirigido por Sebastián Hacher: "Inakayal vuelve: bordar el genocidio Mapuche" (en 2018). Finalmente, se revelan los alcances materiales de la narrativa racista que criminaliza la protesta para justificar el poder disciplinario, tomando como referente la cobertura fotográfica del Paro Nacional de Ecuador de octubre del 2019 realizada por El Colectivo Fluxus y Gualinga.

Palabras clave: mirada; anticolonial; racismo; imagen fotográfica; criminalización.

\section{Abstract:}

The objective of this article is to explain the heterogeneity of the gaze, the symbolic and material scope of the representation, for which photographic texts were captured, intervened and documented from an anti-colonial perspective are analyzed. This reflection is carried out from a multilocal-multisituation contrast exercise between the gaze of three photographers: Graciela Iturbide from Mexico, Sebastião Salgado from Brazil and Martín Chambi from Peru, who have different race-class-gender conditions. It also explains how the colonial gaze of racial scientism was subverted in the photographic intervention project directed by Sebastián Hacher: "Inakayal returns: embroidering the Mapuche genocide" (in 2018). Finally, the material scope of the racist narrative that criminalizes protest to justify disciplinary power is revealed, taking as a reference the photographic coverage of the Ecuadorian National Strike in October 2019 by El Colectivo Fluxus and Gualinga.

Keywords: gaze; anticolonial; racism; photographic image; criminalization. 


\section{Introducción}

A lo largo de este escrito se realiza un análisis semiótico-discursivo revelando a las imágenes como "imágenes-archivo" (Barriendos, 2010) e "imágenes complejas" (Català, 2005), es decir, como "imágenes formadas por múltiples representaciones sedimentadas unas sobre las otras a partir de las cuales se conforma una cierta integridad hermenéutica y una unidad icónica" (Barriendos, 2010, p.135). El modelo analítico que se propone tiene como objetivo acceder a la "interioridad de las imágenes", como explica Català: "efectuar una inmersión en las mismas para poner al descubierto [sus] múltiples e insospechadas dimensiones" y así ir más allá de la "epidermis de la imagen" (p. 21). Este enfoque, para el análisis de la disputa de sentidos, parte de la perspectiva decolonial, la sociología de la imagen, el análisis del discurso y la semiótica de la cultura.

Las categorías analíticas que se usaron fueron principalmente: imagen compleja (Català 2005), imagen-archivo (Barriendos, 2010), archivo (Mbembe, 2002), interseccionalidad (Davis, 2005), memoria de la cultura (Lotman, 1996) y mirada anticolonial: una categoría construida a partir de las premisas de diversos autores (Albán, 2006; Arboleda, 2004; Guerrero, 2004, 2010; Rivera, 2010).

Para explicar a qué se hace referencia con la categoría "mirada anticolonial" es preciso definir la perspectiva desde la que se realizó esta reflexión. Para ello es conveniente tener en cuenta que los diversos pensadores que han planteado la necesidad de construir sus objetos de estudio desde la correlación de fuerzas en la matriz colonial han sido clasificados como autores de la postcolonialidad, la decolonialidad y la decolonialidad; cabe resaltar que estas corrientes de pensamiento tienen diferentes perspectivas teóricas y provienen de diferentes lugares de enunciación y posiciones geográficas. En esta exploración se ha realizado una lectura crítica de autores considerados en las tres corrientes y se ha encontrado que los principales aportes para el presente estudio provienen de quienes tienen una "mirada anticolonial". Esta entrañada forma de mirar emana de quienes han sido atravesados por la herida colonial, aquellos cuyas reflexiones se han originado en la propia experiencia de subalternización, opresión y racialización, siendo esta mirada un posicionamiento político que se agrega a su perspectiva teórica.

En este trabajo se propone que la "mirada anticolonial" está presente en estas tres corrientes teóricas - la postcolonialidad, la decolonialidad y la descolonialidad_en las voces y escritos de investigadores que han repolitizado la mirada de sus 
lectores al Ilevar el análisis de la colonialidad, que los interpela día a día, a los múltiples espacios del poder, incluidos los regímenes de representación.

Para aproximarnos a la heterogeneidad de la mirada, pensemos en las narrativas desobedientes, que hacen parte de los regímenes de representación contrahegemónicos y tienen un horizonte histórico profundo; están sedimentadas en la "memoria de la cultura" (Lotman, 1996) y en la mirada: en nuestra forma de ver desde nuestra "cosmo-existencia" (Guerrero, 2007), es decir, desde el lugar que ocupamos en el mundo.

En las narrativas desobedientes podemos observar que existen una diversidad de miradas con relación a los grados de opresión que hemos internalizado y que nos han impuesto desde la colonización. Los diferentes niveles de opresión son resultado de la intersección entre las condiciones de raza, clase y género, como explica Angela Davis (2005). Sin embargo, es posible diferenciar entre dos miradas antagónicas: la mirada colonial y la "mirada anticolonial".

La mirada colonial se construye desde las narrativas que se instituyen en los regímenes de representación dominantes. La mirada anticolonial, por otro lado, es construida de manera crítica desde narrativas que desobedecen a ese régimen. Es posible entonces asegurar que ambas miradas se encuentran en disputa, y de esa reflexión deriva una de las premisas principales de esta investigación: la guerra de guerrillas de sentidos. La categoría "guerra de guerrillas" de Ernesto Che Guevara (1960) se lleva al campo del sentido para evidenciar la asimetría en que se da la disputa simbólica y su carácter multisituado. Dicha asimetría limita el alcance de la representación desobediente, desde la que se insurge y se resiste mediante tácticas para detonar la memoria de la cultura insurgente. En cambio, desde el régimen narrativo dominante se movilizan estrategias con alcances simbólicos y materiales, acerca de los cuales se reflexiona en este artículo.

\section{La mirada enraizada en la imagen-archivo}

Con el fin de explicar la heterogeneidad de la mirada detrás de estos regímenes de representación pensemos en la fotografía. Inicialmente debemos tener presente que podemos acercarnos a la mirada del fotógrafo analizando su condición material. Podemos indagar en la región del mundo a la que pertenece y qué papel juega este territorio dentro de la división internacional del trabajo, y de ese panorama general aproximarnos a su lugar de enunciación. Es decir, a su condición de clase, raza, género, 
realizando preguntas que nos den información acerca de la mirada de los productores de estas narrativas, y no solo de los aspectos formales de la imagen.

En una reflexión realizada desde la matriz colonial la condición de raza es imprescindible, y para indagar en torno a los fundamentos materiales. Además, es necesario tomar en cuenta la condición de clase, lo cual implica comprender el carácter antagónico de la lucha de clases y el funcionamiento de la correlación de fuerzas, las cuales están determinadas por el lugar que ocupamos en el mundo. Por ejemplo, si formamos parte de una nación enraizada, que ha sido "encapsulada"—en términos de Yasnaya Aguilar (2019) - dentro de un Estado nación hegemónico cuya ideología fue construida tras la colonización, con símbolos y prácticas políticas y culturales ajenas; el lugar que ocupamos es en muchos sentidos un lugar que estamos disputando continuamente. Por ello, desde la experiencia encarnada, es decir, la experiencia que nos ha atravesado el cuerpo, conocemos el funcionamiento de la subalternización por nuestra condición de raza-clase.

Finalmente, es preciso tener presente que las asimetrías no se restringen a nuestra condición de raza y clase, sino que también se extienden hacia nuestra condición de género, aunque siempre entrelazadas. La disputa que ha atravesado nuestro cuerpo está fundada en los marcadores de control determinados por la raza y los mecanismos de subalternización definidos por la clase; son tres condiciones establecidas en la división internacional del trabajo, porque es resultado de la división misma del territorio entre invasores e invadidos.

Es necesario subrayar que al evidenciar dicho lugar de enunciación podemos entender las condiciones de producción y de circulación de las obras, pues a partir de la intersección raza-clase-género se han configurado las asimetrías que no permiten que determinados discursos sean amplificados.

En consecuencia, existen "experiencias silenciadas" (Arboleda, 2004) y narrativas que destacan por la "visibilización negativa" (Albán, 2006) que hacen de determinadas naciones, estratos, clases sociales o identidades de género. Para ilustrar la importancia del lugar de enunciación en relación con la mirada, consideremos la intersección razaclase-género de tres fotógrafos del siglo XX: Graciela Iturbide, Sebastião Salgado y Martín Chambi. Para este ejercicio analítico se seleccionaron estos tres productores de "imágenes-archivo" porque su trabajo es contrastable; Iturbide enfatiza la dimensión estética, Salgado la dimensión política y Chambi se aproxima a la imagen compleja, pues logra fotografías en las que existe recursividad entre las dimensiones estéticapolítica-emotiva. 
La fotógrafa mexicana Graciela Iturbide, quien nació en 1942, cuenta con un vasto trabajo fotográfico realizado en la segunda mitad del siglo XX. La coyuntura de la emergencia del discurso visual de esta autora revela su condición de privilegio respecto de las mujeres que retrata, como la mujer Seri de Mujer ángel (1979) o la mujer de Juchitán Oaxaca Nuestra señora de las iguanas (1979). Las protagonistas de ambas fotografías pertenecen a una raza-clase que accedió a la tecnología fotográfica cuando esta artista ya se encontraba consagrada.

Figura 1. Mujer ángel

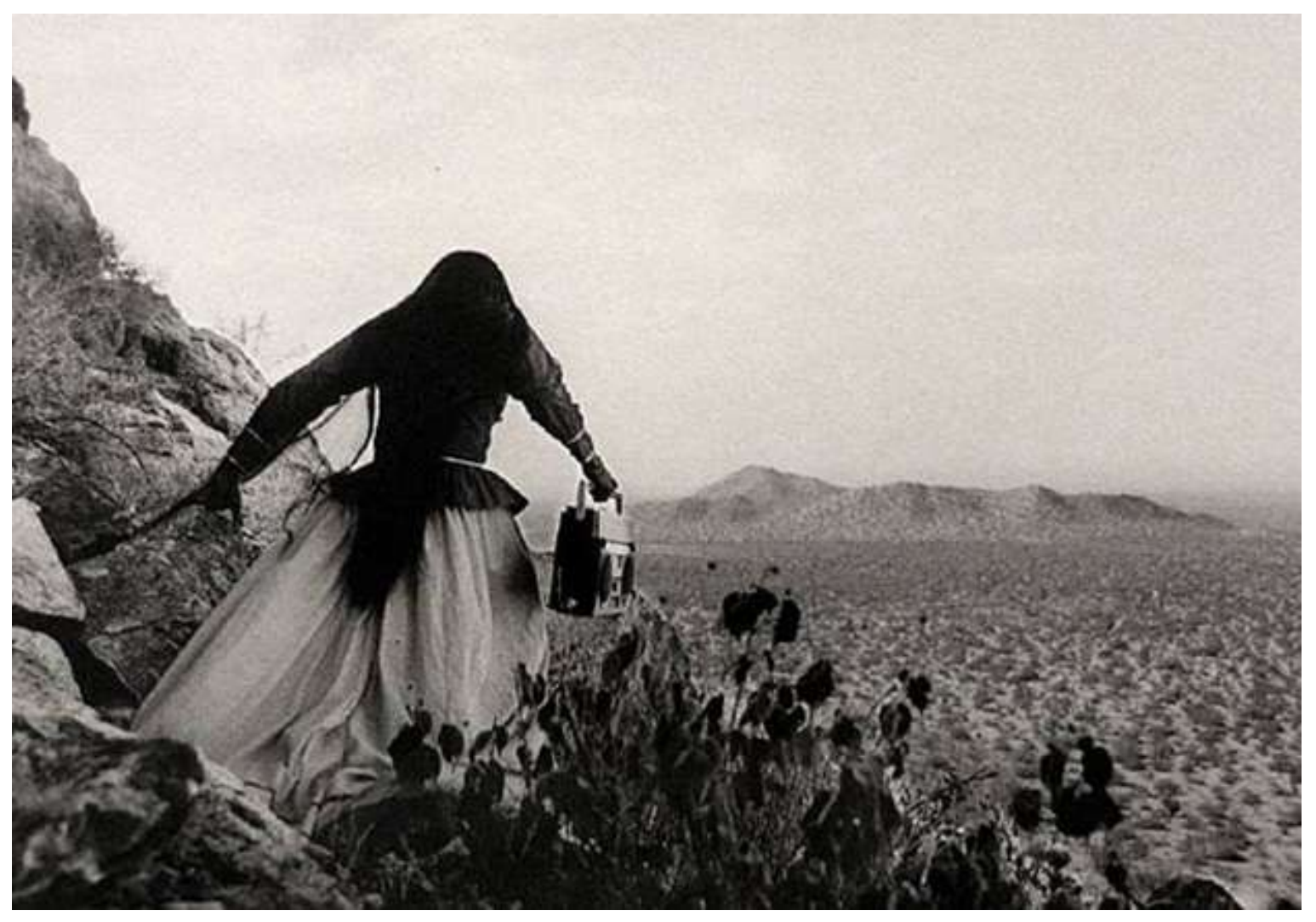

Fuente: Iturbide, México, 1979.

El resultado de la asimetría, entre la que posee la cámara y quien es retratada por ella, es un discurso unilateral en el que Iturbide recrea su imaginario acerca de las mujeres que captura con su lente. De acuerdo con la clasificación que Bill Nichols (1997) hace de las miradas, Iturbide tiene una mirada clínica y profesional, en la que 
la fotografía "se sitúa dentro del espacio ambivalente entre el registro distanciado y la respuesta compasiva" (p. 127).

Para continuar nuestra reflexión acerca de la heterogeneidad de la mirada, podemos agregar la condición de género, contrastando el lugar de enunciación de Graciela Iturbide con el del fotógrafo brasileño Sebastião Salgado, quien nació en 1944 y es su contemporáneo. La exploración fotográfica de Salgado atravesó fronteras y conflictos. Ha trabajado en decenas de países documentando la explotación y el destierro, ejemplo de ello son las obras fotográficas Otras Américas (1986), Sahel: O homem em pánico (1986) y Sahel: O fim do caminho (1988), Trabajadores (1993), Tierra (1997), Éxodos y Retratos de los niños del éxodo (2000), El fin de la polio (2003) y Génesis (2004).

Figura 2. Gold. La fiebre de oro

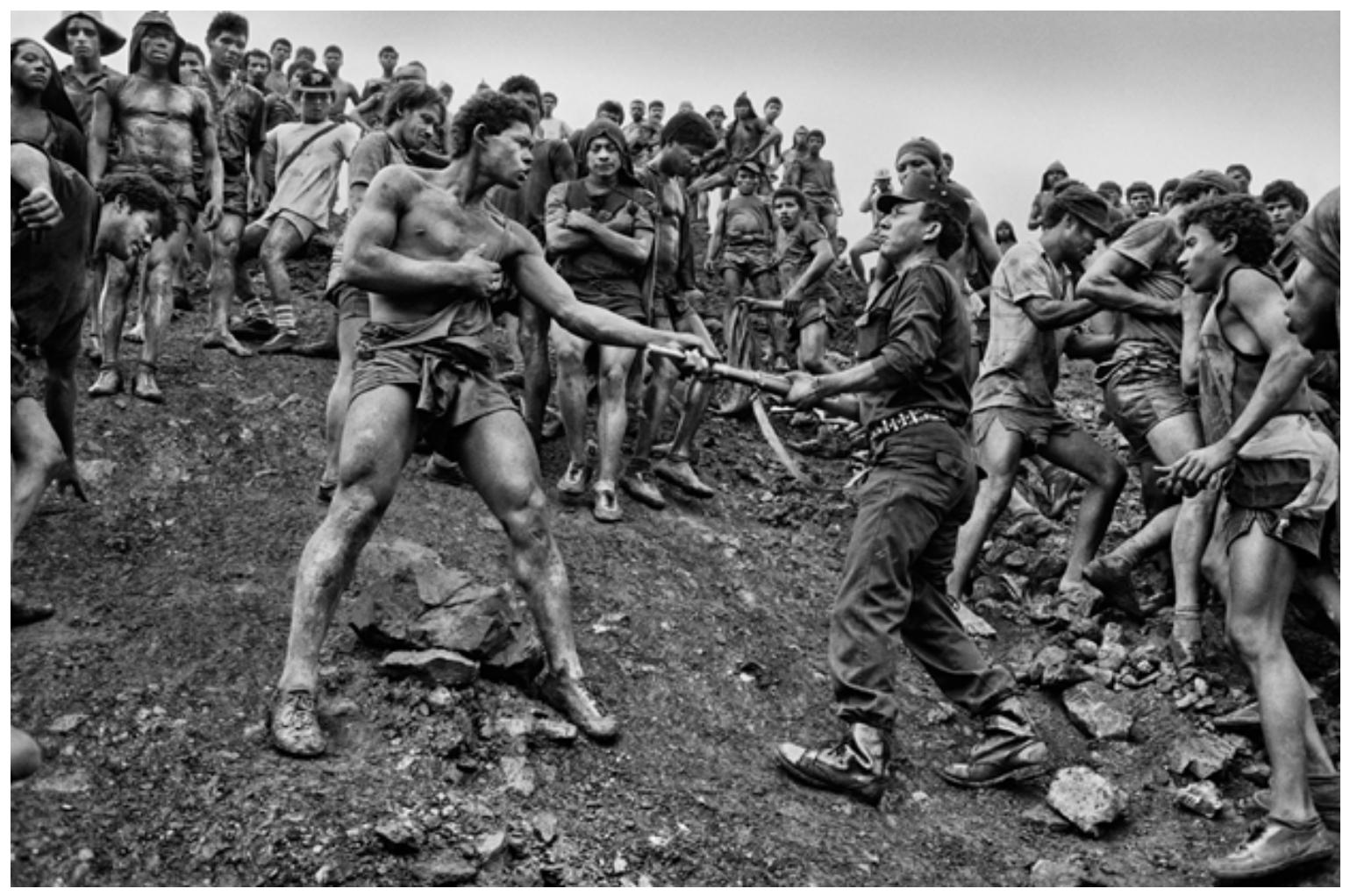

Fuente: Salgado, S., Brasil, 1986.

La producción y circulación de su obra es global, en contraste con la de Iturbide, en gran medida debido a que Salgado logró darle un uso político a su condición. 
Es importante destacar que los privilegios de Salgado no solo son de raza-claseen relación con sus compatriotas y congéneres de otras latitudes, que como en el caso de México no tenían acceso a las costosas herramientas fotográficas del siglo XX-; sino también en cuanto a su condición de género, por la que pudo eludir los riesgos que una mujer debe afrontar cuando se coloca detrás de la cámara en zonas de conflicto. La mirada impotente (Nichols, 1997) de Salgado se caracteriza por la indefensión "una marca estilística evidente de un observador o agente autoral que se siente obligado a seguir observando sin dejar de indicar su incapacidad para intervenir" (p. 123).

La mirada de ambos fotógrafos guarda una distancia con los sucesos y personajes retratados. No es una "mirada encarnada" en la problemática, es más bien una mirada fraterna y en el caso de Iturbide es en muchos aspectos también una mirada indigenista; sublima los rasgos culturales de las mujeres que retrata. Sin embargo, no se acerca a los múltiples conflictos que también son constitutivos de su identidad.

Figura 3. Primera motocicleta en el Cusco de Mario Pérez Yáñez

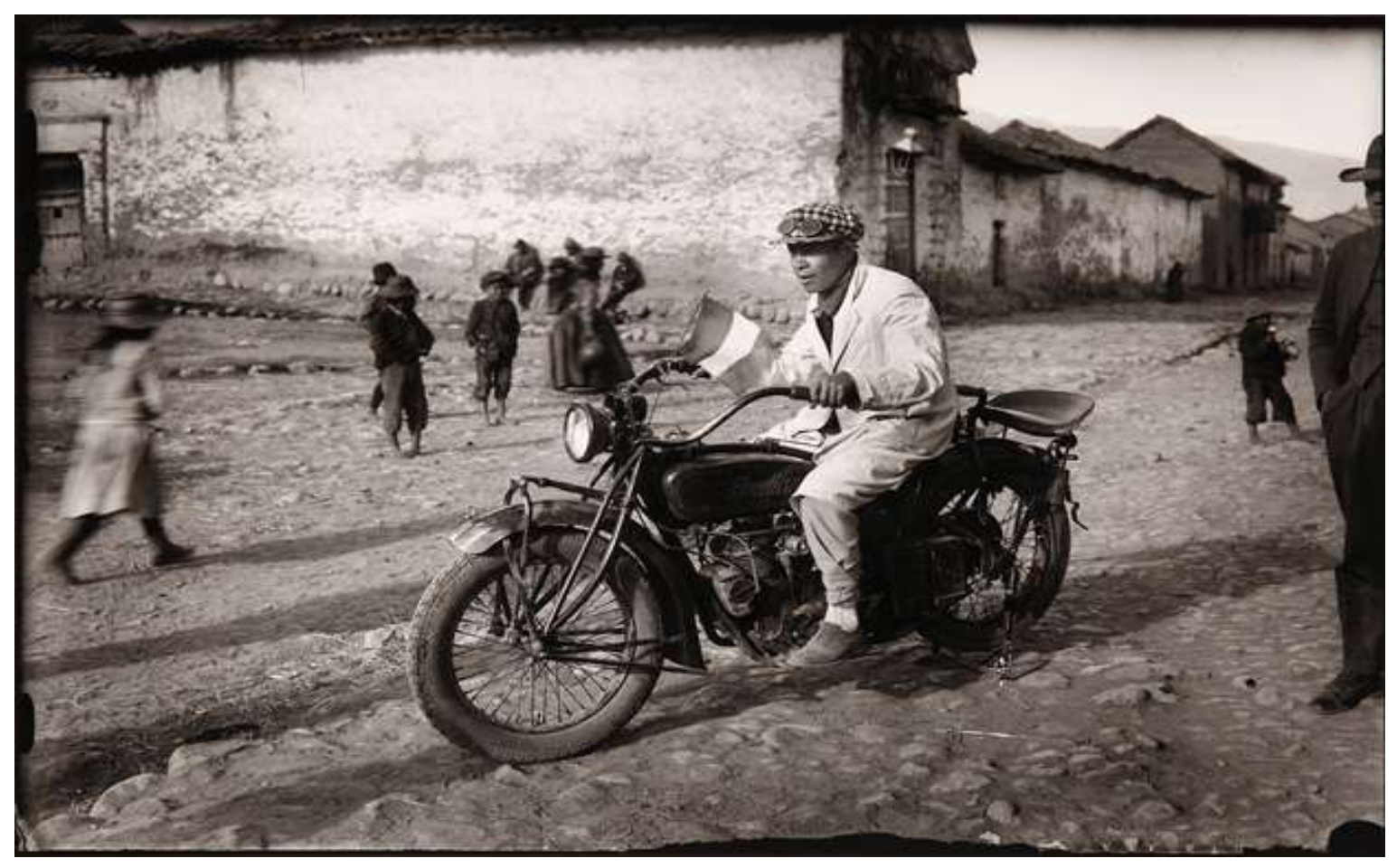

Fuente: Martín Chambi, Perú, 1930. 
En contraste, las imágenes de Salgado muestran el rostro más crudo de la explotación, aunque solo son realizadas en coyunturas específicas; su trabajo consiste en documentar realidades que no lo atraviesan y en las que está inmerso durante su estadía levantando imágenes. En cambio, la mirada de Martín Chambi, de origen qhichwa, es una mirada que se encuentra enraizada en el territorio que plasma en sus fotografías y que sublima tanto las prácticas culturales o los conflictos en las que está inmerso y también la vida cotidiana de la cultura a la que pertenece, como la fotografía de la Primera motocicleta en el Cusco de Mario Pérez Yáñez (1930).

Martín Chambi nació en Coaza, Puno, Perú en 1891 y murió en 1973. Formó parte de la Escuela Cusqueña de Fotografía y su trabajo fue reconocido desde la primera mitad del siglo XX, cuando en su región andina se encontraban en disputa dos narrativas que representaban a las naciones enraizadas; como explica Ulises Zeballos Aguilar (2002): la narrativa de los gamonales y la de los indigenistas.

Figura 4. Campesinos en el juzgado

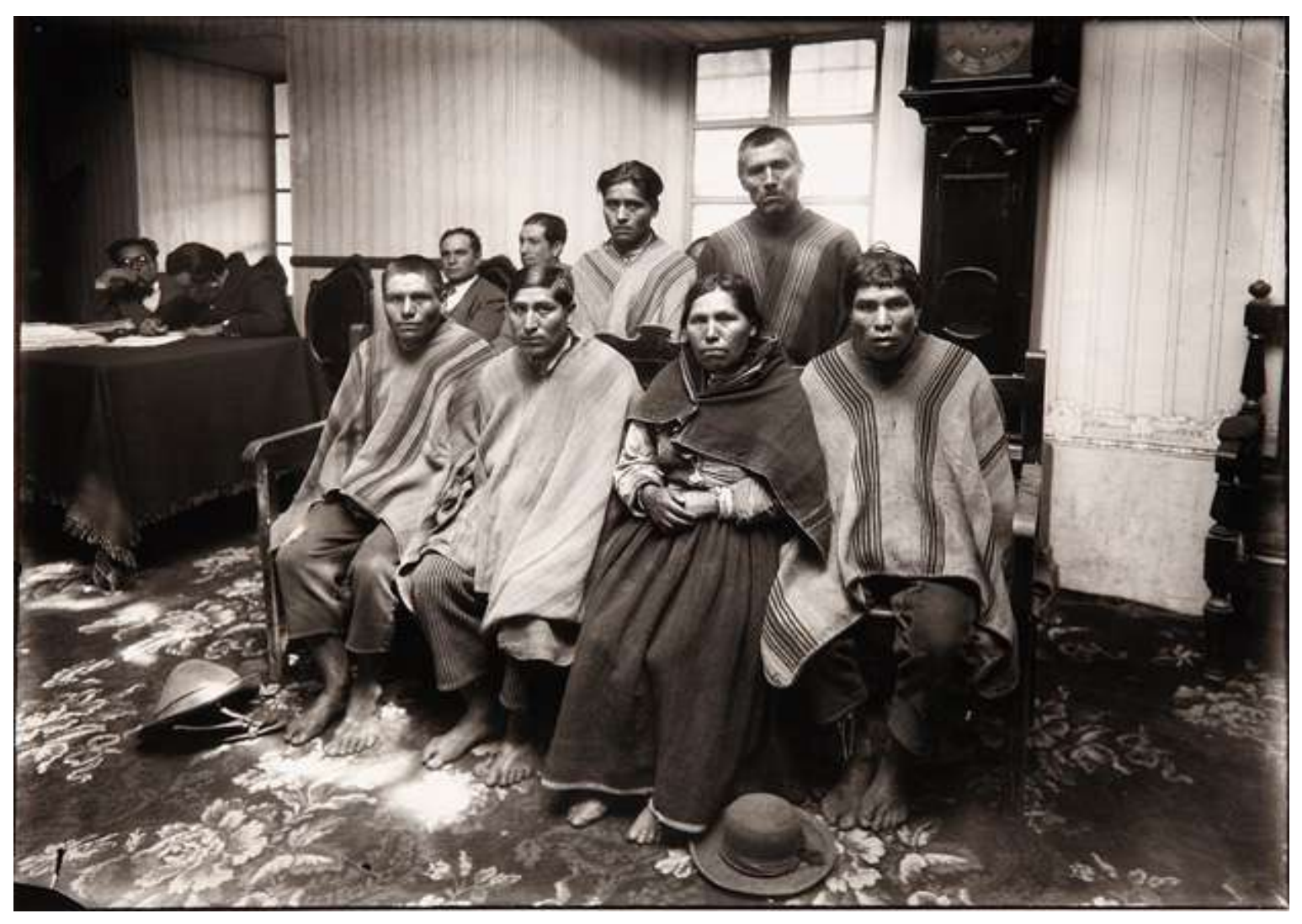

Fuente: Martín Chambi, Perú, 1929. 
La narrativa de los gamonales juzgaba a los integrantes de estas naciones como "salvajes, vengativos y con instintos animales" (Zeballos, 2002, p. 80) y la narrativa de los indigenistas los consideraba como el ideal peruano, como "nuevos indios" con sus tradiciones, pero asimilados en la cultura mestiza. En ambas narrativas, quienes los representaban no pertenecían a estas naciones enraizadas. En cambio, Chambi sí poseía la competencia narrativa y simbólica para lograr fotografías hondas, por ejemplo: Campesinos en el juzgado (1929), donde es posible analizar profundos sedimentos de la memoria de la cultura (Lotman 1996) y no solo rasgos coyunturales.

Los retratos realizados por Chambi, como Campesino de Calca (1926), están permeados por la estética (colonial) de la época. Sin embargo, poseen una cualidad sumamente importante: revelan la intimidad del retratado más allá de la herida colonial.

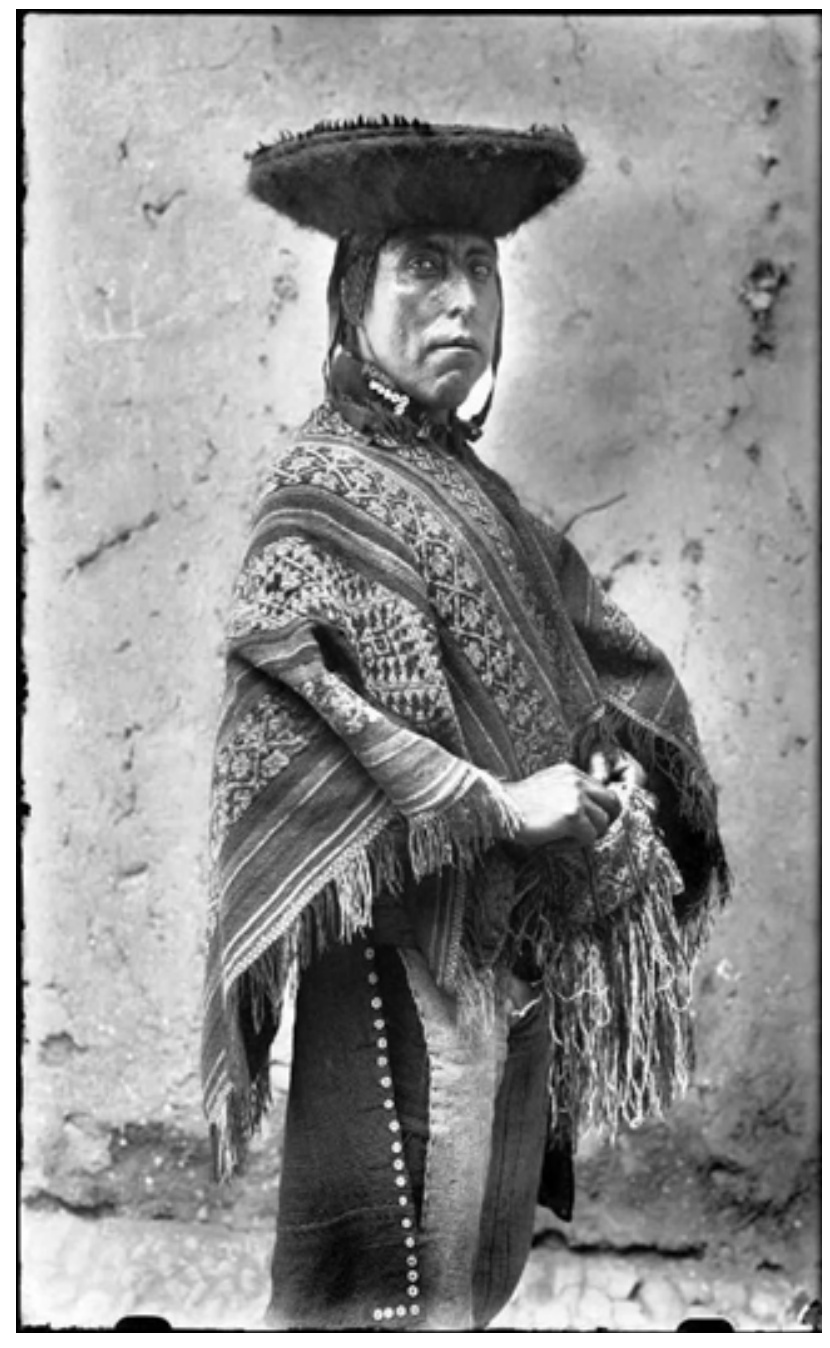

Figura 5. Campesino de calca

Fuente: Martín Chambi, Perú, 1926. 
Es preciso subrayar que ante la cámara de Martín Chambi se ve a mujeres, hombres, niños y abuelas posar alegres y altivos; en un estudio fotográfico, en la comunidad y en su vida cotidiana. De ahí que en sus fotografías se pueden apreciar rostros y rasgos milenarios mostrándose de la forma en que los retratados querían trascender en la imagen.

La fotografía de Martín Chambi proviene de una mirada enraizada en la comunidad, la cual es una forma de ver que no solo logra desvanecer las asimetrías entre el que capta la imagen y el que la protagoniza; también se convierte en el detonador de una diversidad de emociones, más allá de un ensueño como La mujer ángel (1979) de Graciela Iturbide, o de una denuncia como la notable obra de Salgado.

En consecuencia, al analizar la obra de Chambi como "imágenes-archivo" podremos acercarnos a la "imagen compleja", pues en ella existen no solo múltiples sedimentos, sino que también es transdimensional, se trata de una representación que proviene de una "mirada enraizada" y de un proceso estético-político-emotivo entre quienes logran reconocerse como parte de una misma historia, no solo de agravios, sino también de sueños, resistencias, luchas y fiestas.

\section{La intervención de la mirada}

Conocer el lugar de enunciación es un elemento indispensable para acercarse a la mirada del realizador. Sin embargo, lo que le da el carácter de anticolonial a la mirada no depende solo del fotógrafo, también es resultado de un diálogo entre el productor de imágenes y el receptor. Una imagen que proviene de una mirada colonial puede ser subvertida por el receptor que la analiza o interviene para convertirla en un dispositivo visual emancipador-anticolonial. Un ejemplo de ello es el Proyecto "Inakayal vuelve: bordar el genocidio Mapuche" (2018), un trabajo colectivo dirigido por Sebastián Hacher. 
Figura 6. Lonko Inakayal

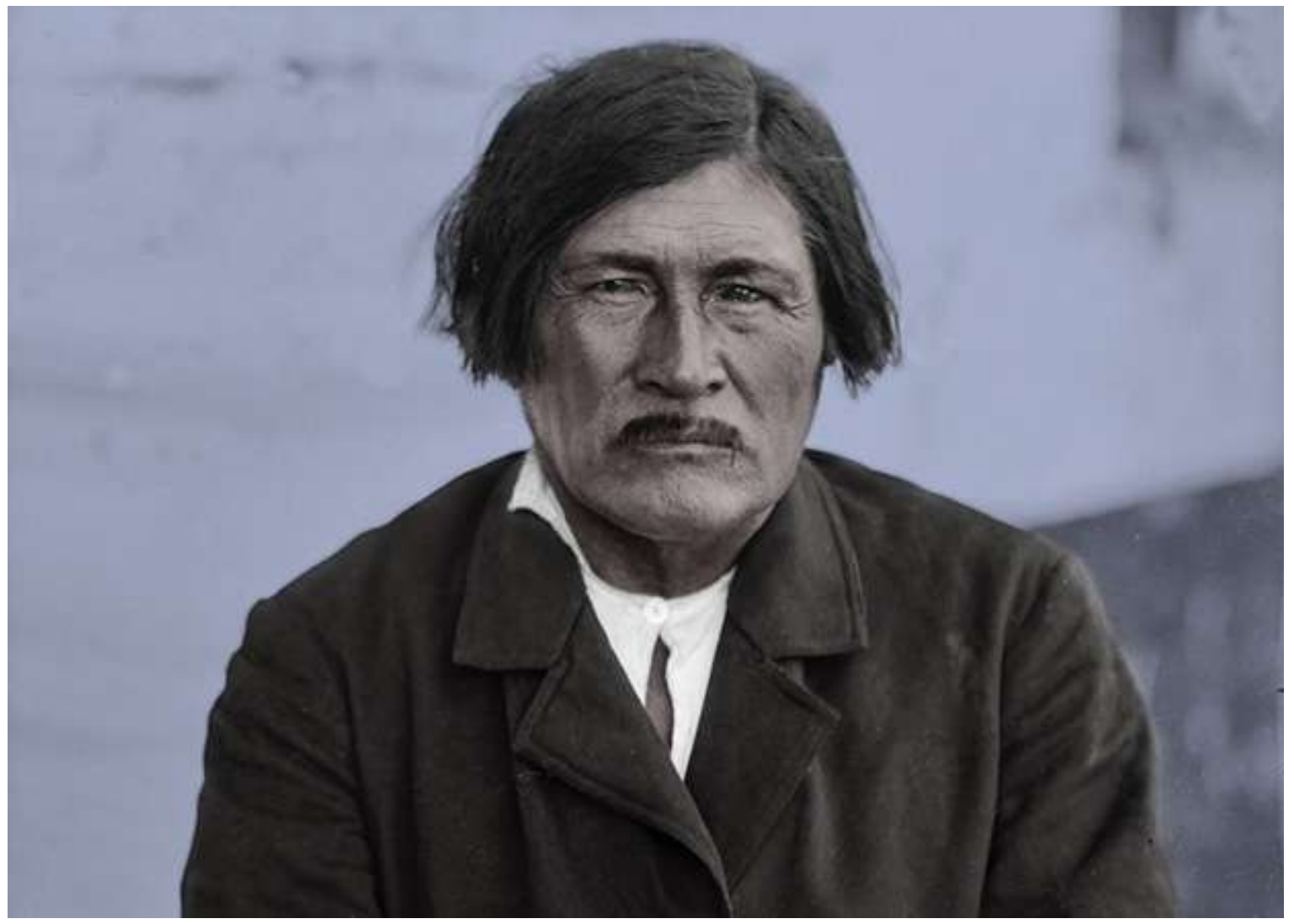

Fuente: Museo de Ciencias Naturales de La Plata, Argentina, 2017.

En este proyecto se intervinieron fotografías de prisioneros Mapuche que pertenecían a las familias de los Lonkos Sayhueque, Inakayal, Foyer y Chagallo, quienes sobrevivieron a "La marcha de la muerte" (1885) y luego fueron trasladados como prisioneros al Museo de Ciencias Naturales de La Plata, donde los "estudiaron" y fotografiaron desde la mirada colonial del cientificismo racial (Hacher, 2017, 2018). 
Figura 7. Trukel, hijo del Lonko Sayhueque.

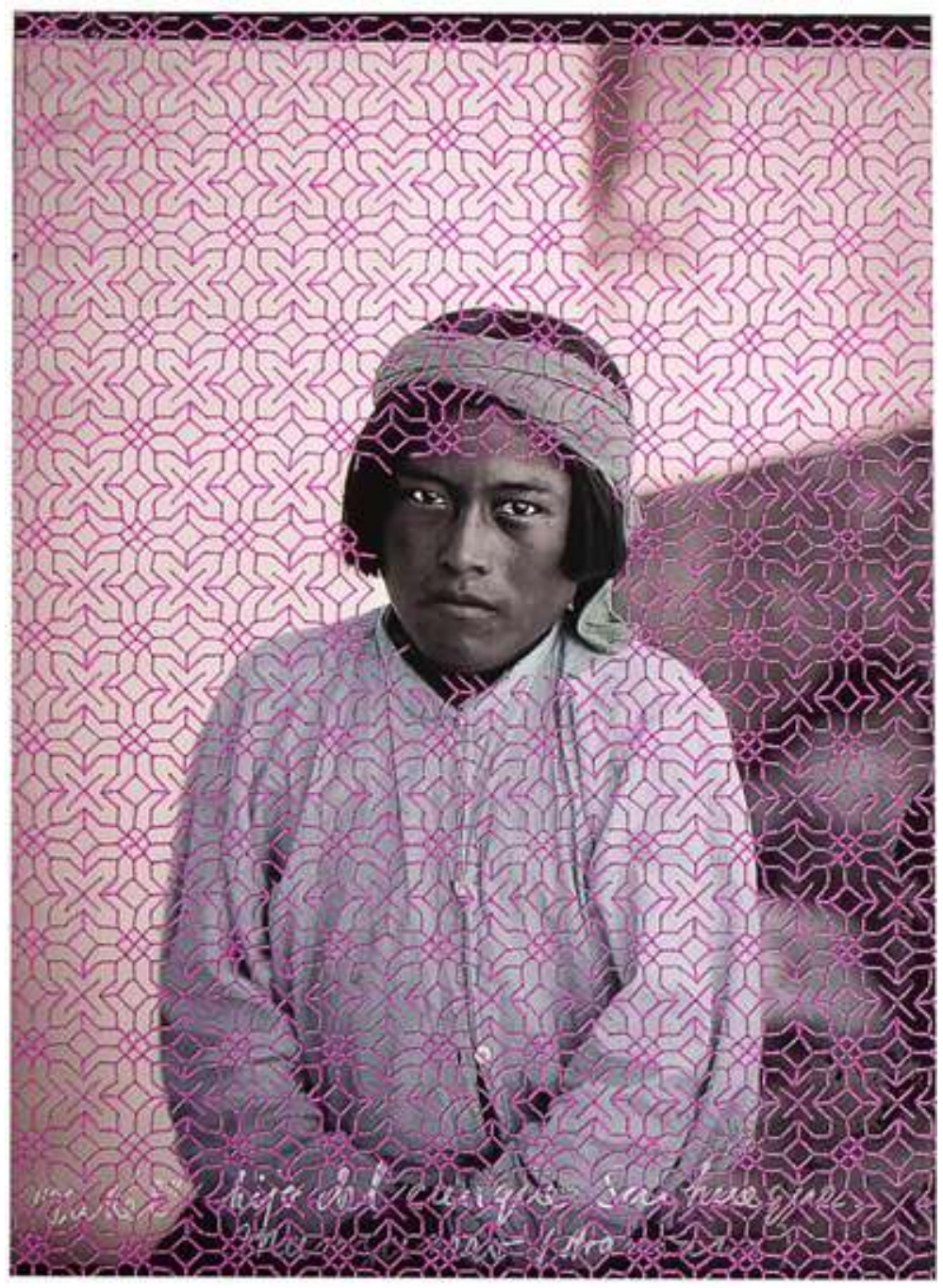

Fuente: Museo de Ciencias Naturales de La Plata, Argentina, 2018.

La palabra Lonko en idioma mapudungun significa "cabeza" y se refiere a los jefes de un grupo de familias o de una comunidad. Por dicha posición y el aprecio que la comunidad le tiene al valiente Inakayal, él se convirtió en uno de los símbolos de la resistencia al genocidio Mapuche y por ello este proyecto lleva su nombre. Las fotografías de las familias de estos Lonkos Mapuches se tomaron entre 1886-1888 y se captaron desde el canon que caracterizaba a los retratos antropométricos. 
Figura 8. Intervención de la fotografía por la comunidad Mapuche

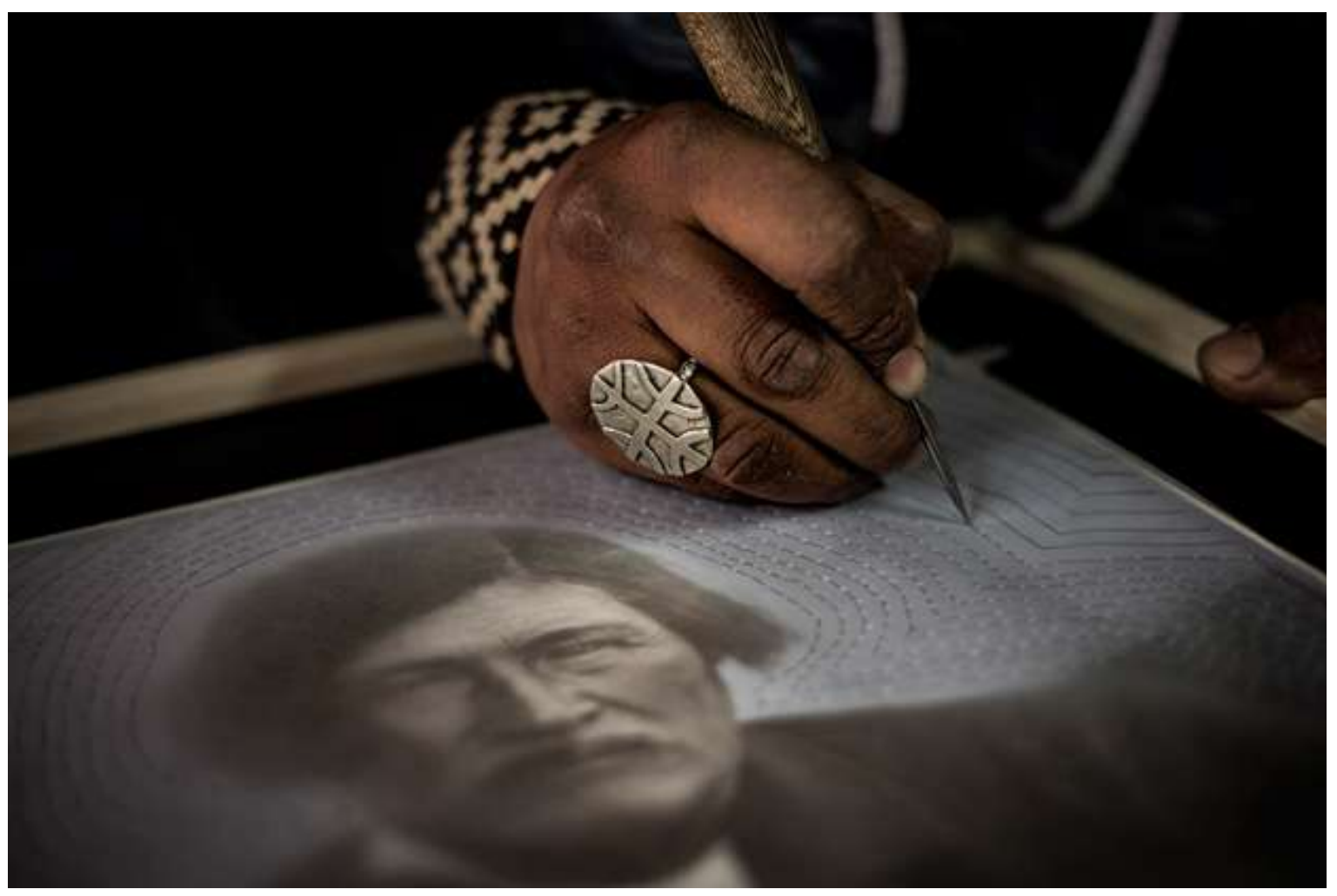

Fuente: Proyecto Inakayal vuelve, Argentina, 2018.

En 2018 Hacher "iluminó" 12 de estas imágenes. Él explica que las intervino porque "Pintar la representación gráfica de un genocidio es un intento por insuflar vida donde otros sembraron masacres" (Hacher, 2017).

Un año más tarde, Sebastián Hacher reflexiona en el proceso de restitución que motivó este proyecto y expresó: "las había pintado para sacarlas de la oscuridad en las que fueron tomadas. Bordaba sobre ellas para devolverles la fuerza que les habían robado" (Hacher, 2018).

La intervención de estas fotografías tuvo como objetivo subvertir su sentido y repolitizar la mirada respecto al genocidio Mapuche. El proyecto se convirtió en una "intervención comunitaria itinerante" cuando Hacher devolvió las imágenes a descendientes Mapuches y compartió el proceso de bordado como un ritual de sanación, pero además al hacer caminar a las imágenes para "Rebobinar la marcha de la muerte" (Hacher, 2019), recogiendo los pasos de los ancestros Mapuches. 
En consecuencia, el bordado como ritual-comunitario tuvo como principal motivación restituir de manera simbólica la dignidad y la fuerza de esta nación que resiste a la ocupación colonial.

En el caso del proyecto "Inakayal vuelve: bordar el genocidio Mapuche", la intervención de la imagen mediante el bordado ritual-sanador-comunitario logró restituir de manera simbólica la dignidad y la fuerza de este y otros Lonkos mapuches. En cambio, en el caso de las imágenes que son domesticadas por las fuerzas públicas para perseguir a los insurrectos, los alcances de la imagen son más de carácter material que simbólico.

El proyecto de Hacher logró subvertir la mirada colonial que habitaba las fotografías, en primer lugar, porque al "iluminarlas" y bordarlas, como un "ritualsanador-comunitario-itinerante", las sacaron de la oscuridad en las que fueron producidas. En segundo lugar, porque idearon una manera de hacer caminar a las imágenes, sustrayéndolas del silencioso sepulcro del museo donde habían sido clasificadas y archivadas como escombros de la "memoria de la cultura insurgente" de la nación Mapuche. En consecuencia, el acto de la intervención de estas fotografías las transmutó en "un lugar para habitarlo, desde donde poder seguir expresándose" (Mbembe, 2002, p. 25).

Sin embargo, no solo la imagen racista puede ser subvertida en su sentido, ya que las imágenes captadas desde una mirada anticolonial pueden convertirse en un arma de contrainsurgencia. En el caso de la fotografía documental, esto es posible por la presunción de objetividad que posee y el uso que se le da como evidencia de la realidad. Por ello, este tipo de fotografía es el ejemplo más claro para acercarnos a los alcances tanto simbólicos, como materiales de la representación. Siguiendo con la imagen fotográfica, cabe preguntarnos cómo se conforma el imaginario racista cuando aquello que el fotógrafo captó desde su lugar de enunciación entra en diálogo con la mirada de múltiples receptores. Así mismo, cómo la circulación de estas imágenes sirve como justificación de la criminalización y el disciplinamiento violento contra el cuerpo desobediente. Tomemos como ejemplo las protestas en Ecuador durante el Paro Nacional que se oponía a las medidas económicas y las reformas que el Gobierno de Lenin Moreno quería imponer.

En octubre de 2019 los gremios del transporte convocaron a Paro Nacional, como respuesta a la inminente eliminación de los subsidios al combustible y el 3 de octubre se paralizaron las actividades productivas en todo el país. En la disputa política se vislumbraba que tras la realización de una "negociación sectorial" se llevaría a cabo un 
"intercambio particularista" (Ramírez, 2020) y el ajuste estructural se implementaría sin gran oposición. Sin embargo, para el 5 de octubre la Confederación de Nacionalidades Indígenas del Ecuador (CONAIE) — con su experiencia encarnada en levantamientos junto a organizaciones sindicales y una amplia diversidad de insumisos, relevaron a los transportistas y le dieron largo aliento al Paro Nacional, el cual se oponía al neoliberalismo corporativo: al neoliberalismo criollo. Así, según Ramírez (2020) "El Paro de Octubre dibujaba el encuentro entre clase y etnicidad en la reconfiguración de la política de los explotados" (p. 17). El Paro combinó las estrategias de lucha de las naciones enraizadas en el Ecuador con las tácticas de la lucha sindical de la clase trabajadora. Lo anterior, en clave no solo anticolonial, también feminista; las mujeres encabezaron marchas, tomas simbólicas y posibilitaron la continuidad del Paro mediante la organización de los espacios de albergue: "el corazón de la revuelta".

Los integrantes de los Pueblos y Nacionalidades del Ecuador rompieron con el "ritual del olvido" (Mbembe, 2002) y en octubre en vez de conmemorar la irrupción de Colón y acatar las reformas y medidas económicas que se les imponían como una forma de renovar el "derecho de conquista del invasor" (Rivera, 2010); se tomaron las calles y sacudieron con sus protestas el racismo de la nación hegemónica ecuatoriana que los insultó llamándolos bandidos, ladrones, resentidos sociales e incluso correistas. No obstante, El Colectivo Fluxus captó la disputa tanto material como simbólica de estas protestas, logrando fotografías icónicas en su cobertura "Paro Nacional: Ecuador en Resistencia".

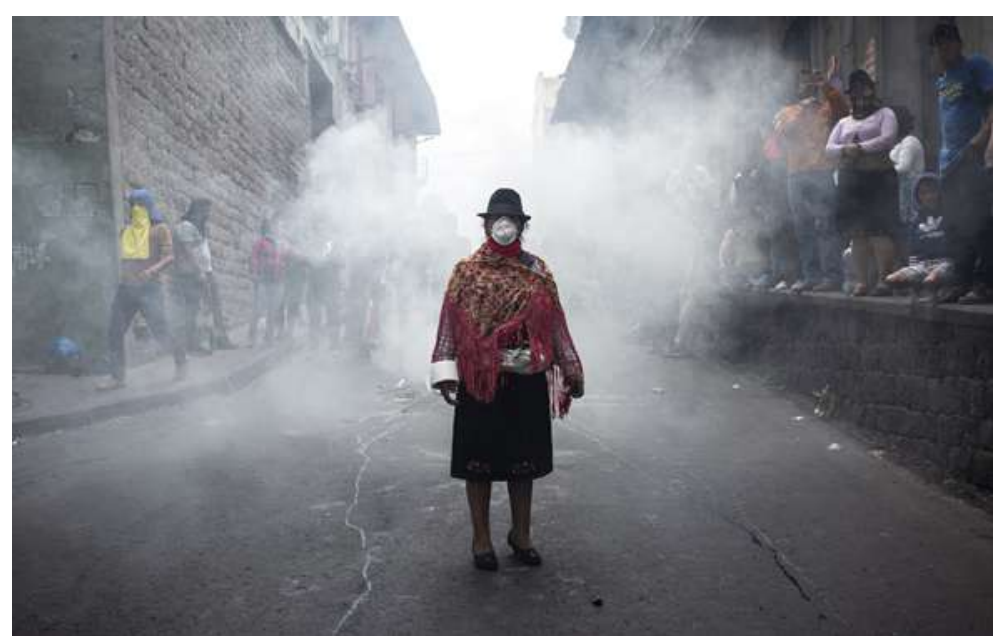

Figura 9. Paro Nacional: Ecuador en Resistencia

Fuente: David Díaz, Colectivo Fluxus, Ecuador, 2019. 
Los señalamientos que se amplificaron durante las protestas validan uno de los argumentos que plantea Carolina Arrunátegui Matos (2010) cuando analiza el discurso racista contra los pueblos amazónicos en la prensa peruana, en el cual enfatiza:

Se le atribuye una agencia 'física' respecto de sus acciones, pero no una agencia "intelectual". El amazónico "amenaza", "advierte", "radicaliza", "ofende", "rompe el diálogo", "impide el acuerdo", se "subleva"; pero todas estas acciones no son realizadas por voluntad propia, sino que hay "alguien detrás" que los conduce. (p. 449)

La tesis de Carolina Arrunátegui es que mediante la estrategia discursiva que contrasta al "nativo bravo" del "nativo amado" se redimen de culpas a los pueblos para darle continuidad al discurso en el que son seres manipulables y necesitamos de tutela. En el caso de Ecuador, los voceros de las organizaciones de sus diversas nacionalidades, incluidas las de la Amazonía, debieron extender comunicados para deslindarse de partidos políticos y del exmandatario Rafael Correa, a pesar de que sus confederaciones tienen una larga historia de lucha por su autonomía.

Figura 10. Paro Nacional: Ecuador en Resistencia

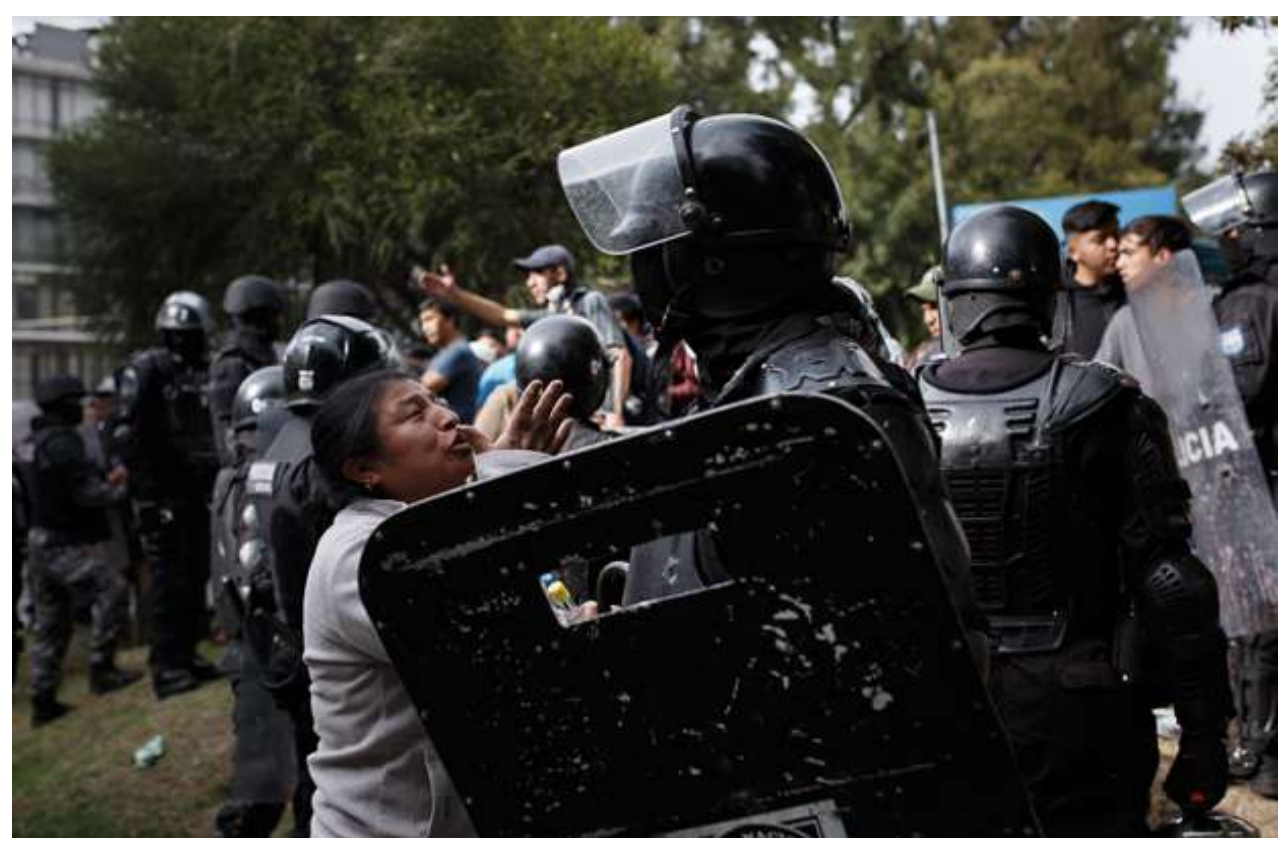

Fuente: Colectivo Fluxus, Ecuador, 2019. 
Las imágenes que circularon en los medios de comunicación masiva a nivel nacional e internacional se centraron en mostrar acciones violentas para persuadir al público de la necesidad de contener las protestas con un uso excesivo de la fuerza pública y justificar así la presencia del ejército en las calles: "reprodujeron el relato gubernamental acerca de la configuración de un escenario golpista, evitaron mostrar la magnitud de las conglomeraciones o evaluar los significados del conflicto" (Ramírez, 2020, p. 31).

Incluso en el discurso del ministro de defensa se renovaron conceptos propios de un estado de guerra interna, usando términos como "insurgencia organizada" o refiriéndose como "centros de abastecimiento" a los lugares donde universitarios brindaron alojamiento y atención médica a los manifestantes, quienes no eran admitidos en los hospitales y estaban siendo criminalizados y perseguidos.

En una entrevista a Jaime Nebot, exalcalde de Guayaquil y líder del Partido Social Cristiano (PSC), un reportero le preguntó si se contaba con suficiente personal de fuerzas públicas y fuerzas armadas, en caso de que integrantes del movimiento indígena arribarán a la ciudad de Guayaquil para expresar su descontento, a lo que Nebot contestó enérgico: "recomiéndeles que se queden en el páramo". La respuesta de Nebot generó mucho descontento entre los pueblos en medio de la disputa de narrativas en las que se les calificaba de manera racista como una amenaza.

Sin embargo, quien tenía una conducta amenazante era Nebot y los medios de comunicación, quienes de manera encubierta estaban pidiendo que se extremaran las medidas de seguridad para impedir la llegada de integrantes de los pueblos y nacionalidades a Guayaquil, la segunda ciudad más importante de Ecuador.

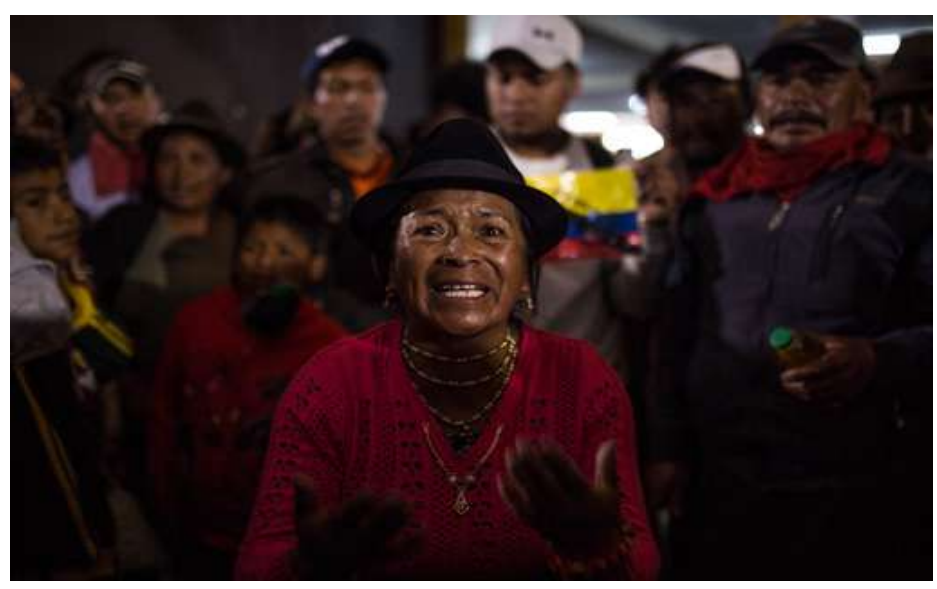

Figura 11. Paro Nacional: Ecuador en Resistencia

Fuente: Colectivo Fluxus, Ecuador, 2019. 
Pero la cobertura que se dio a las manifestaciones no solo provino de las grandes agencias internacionales, el Colectivo Fluxus y fotógrafos independientes salieron también a las calles a registrar los acontecimientos, como por ejemplo Wio Gualinga, quien pertenece al Pueblo Originario Kichwa de Sarayaku de la Amazonía ecuatoriana, quien registró las protestas de su pueblo desde una "mirada encarnada" en la problemática, pues los sucesos atravesaban su cuerpo (colectivo) racializado. El trabajo de estos fotógrafos funcionó como un dispositivo de intervención de la mirada, en el que las imágenes revelan los rostros de las protestas más allá del estereotipo racial o la "visibilización negativa" (Albán, 2006) que se amplificaba en los medios masivos a nivel nacional e internacional con el objetivo justificar el "poder disciplinario" (Foucault, 2009).

Figura 12. Cobertura del paro nacional en Ecuador

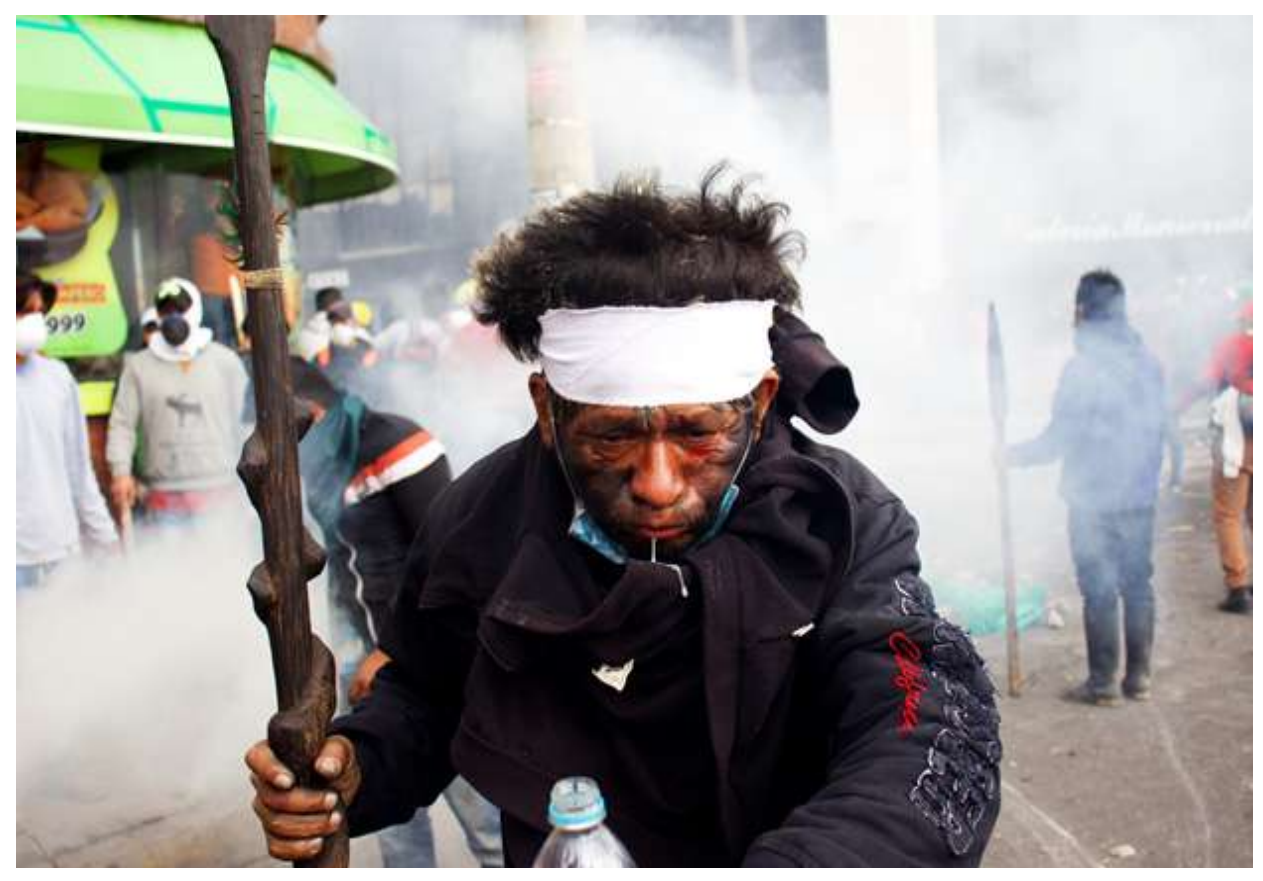

Fuente: Wio Gualinga, Ecuador, 2019. 


\section{Conclusiones}

Los medios de comunicación han funcionado como legitimadores de la criminalización racializadora de la protesta, ejemplo de ello es la cobertura que los medios privados y públicos realizaron durante el Paro Nacional en Ecuador. Sin embargo, la producción y circulación de imágenes encarnadas en la protesta se abrieron paso desde la plaza pública hasta los dispositivos móviles a nivel local, nacional e internacional. Así, la imagen fotográfica alojada en plataformas multimedia y transmedia se dispersó por internet permitiendo que dicha representación se sedimentaria en la memoria de la cultura insurgente. En consecuencia, la disputa simbólica no solo se suscitó en la protesta, durante las acciones insumisas, las marchas, las consignas o las tomas de espacios de poder; también se disputó en los espacios de circulación de las imágenes.

El Proyecto "Inakayal vuelve: bordar el genocidio Mapuche", muestra también la importancia de la creación de espacios de circulación. El proyecto es definido por sus creadores, en su página web, como "una investigación performática, el tendido de una red, una experiencia transmedia de no ficción", permitiendo que la subversión del sentido que posibilita dicho proyecto sea amplificada. Así, el bordado como ritualsanador-comunitario logró restituir de manera simbólica la dignidad y la fuerza de los Lonkos mapuches que habían sido capturados desde el canon(colonial) del retrato antropométrico. Además, repolitizó la mirada respecto al genocidio mapuche; incluso re-actualizó la memoria en torno a la resistencia de esta nación, es decir, re-actualizó la memoria de la cultura insurgente.

La posibilidad de rehabitar las imágenes que han sido producidas desde la mirada colonial es una potente entrada para intervenir la mirada, para subvertir el sentido desde el que fueron capturadas. La producción de imágenes desde la mirada encarnada, es decir, desde la experiencia de la subalternización y/o criminalización que atraviesa al cuerpo racializado, también se da desde un espacio de disputa: simbólica y material. Por ello, es sumamente importante comprender la heterogeneidad de la mirada y crear espacios para la circulación de fotografías y materiales audiovisuales o transensoriales, en los cuales se potencie el uso de la fotografía como dispositivo visual anticolonial. 


\section{Referencias}

Aguilar, Y. (2019). Un nosotrxs sin Estado. OnA ediciones.

Albán, A. (2006). "Conocimiento y lugar: más allá de la razón hay un mundo de colores". En Texiendo textos y saberes. Cinco hilos para pensar los estudios culturales, la colonialidad y la interculturalidad (pp. 59-82). Editorial Universidad del Cauca, Colección Estudios (Inter)culturales.

Arboleda, S. (2004). Intelectualidades afrolatinoamericanas: pasos silenciados y senderos palpitantes. Universidad Andina Simón Bolívar.

Arrunátegui, C. (2010). El racismo en la prensa escrita peruana. Un estudio de la representación del Otro amazónico desde el Análisis Crítico del Discurso. Revista Discurso y sociedad, 4(3), pp. 428-470.

Barriendos, J. (2010). La colonialidad del ver. Visualidad, capitalismo y racismo epistemológico. En Desenganche. Visualidades y sonoridades otras (pp. 130-156). La Tronkal.

Català, J. (2005). La imagen compleja. La fenomenología de las imágenes en la era de la cultura visual. Universidad Autónoma de Barcelona.

Davis, A. (2005). Mujeres, raza y clase. Ediciones Akal.

Foucault, M. (2009). Vigilar y castigar. Siglo XXI.

Guerrero, P. (2004). Usurpación simbólica, identidad y poder. La fiesta como escenario de lucha de sentidos. Ediciones Abya-Yala.

(2007). Corazonar. Una antropología comprometida con la vida. Miradas otras desde Abya Yala para la descolonización del poder, del saber y del ser. Ediciones FONDEC.

Guevara, E. (1960). Guerra de guerrillas. Oceansur.

Hacher, S. (2017, 22 de agosto). Arte, vida y masacres. Bordar el genocidio Mapuche. Revista Anfibia. http://revistaanfibia.com/cronica/bordar-el-genocidio-de-los-mapuche/ Hacher, S. (2018, 22 de junio). Inakayal vuelve. Rebobinar la marcha de la muerte. Revista Anfibia. http://revistaanfibia.com/cronica/rebobinar-la-marcha-de-la-muerte/

Lotman, I. (1996). La semiosfera I. Semiótica de la cultura y del texto. Ediciones Cátedra.

Mbembe, A. (2002). The Power of the Archive and Its Limits. En C. Hamilton et al., Refiguring the Archive (pp. 19-26). Springer.

Nichols, B. (1997). La representación de la realidad. Cuestiones y conceptos sobre el documental. Editorial Paidós. 
Ramírez, F. (2020). Paro pluri-nacional, movilización del cuidado y lucha política. Los signos abiertos de Octubre. En F. Ramírez (ed.), Octubre y derecho a la resistencia. Revuelta popular y neoliberalismo autoritario en Ecuador. CLACSO.

Rivera, S. (2010). Violencias (re)encubiertas en Bolivia. Otramérica.

Zeballos, U. (2002). Indigenismo y nación: Los retos a la representación de la subalternidad aymara y quechua en el Boletín Titikaka, (1926-1930). Instituto Francés de Estudios Andinos (IFEA). 